One of the standard treatments in laryngeal cancer is radiotherapy (RT). Many short- and long-term complications can occur in the region that has received radiotherapy. Definitive treatment of the emerging complications is still debatable, and treatment is challenging for radiation oncologists and ear nose throat specialists. Recently, hyperbaric oxygen treatment (HBOT) has become a promising alternative for the treatment of these complications. The aim of this report is to discuss the effectiveness of HBOT in the treatment of late-term RT-related potential complications in a patient with laryngeal cancer.

We applied HBOT for a 58-year-old male patient with laryngeal cancer for the treatment of laryngeal oedema, and dyspnoea that developed one year after RT. In a decompression chamber at $2.4 \mathrm{~atm}$ pressure, the patient was made to breath $100 \%$ oxygen with a mask for 90 minutes. At the beginning, HBOT was planned for 30 days; however, it was terminated upon improvement of the symptoms at the $19^{\text {th }}$ session. The symptoms, which developed one year after RT, were relieved completely with HBOT, and the patient is maintaining his life without any complaint under our control.

The HBOT can be an alternative treatment for late-term complications developed after radiotherapy. It can be especially used for laryngeal oedema, and dyspnoea related to the field of radiotherapy.

Key words: laryngeal neoplasms, radiation injuries, laryngeal oedema, hyperbaric oxygenation, dyspnoea.

Contemp Oncol (Pozn) 2018; 22 (3): 202-204 DOI: https://doi.org/10.5114/wo.2018.78945

\section{Hyperbaric oxygen therapy in the treatment of complications of irradiation in laryngeal cancer}

\author{
Gonca Hanedan Uslư ${ }^{1}$, Gamze Çebi ${ }^{2}$, Bengü Çobanoğlu \\ ${ }^{1}$ Department of Radiation Oncology, Kanuni Research and Education Hospital, Trabzon, \\ Turkey \\ 2Department of Underwater and Hyperbaric Medicine, Kanuni Training and Research \\ Hospital, Trabzon, Turkey \\ ${ }^{3}$ Department of Otorhinolaryngology, Karadeniz Technical University, School of Medicine, \\ Trabzon, Turkey
}

\section{Introduction}

For more than 60 years, external-beam radiation has been used for squamous cell laryngeal carcinoma treatment. Due to new developments in the technology of radiation therapy and existing trends of organ-sparing protocols while treating advanced-stage laryngeal tumours, radiotherapy (RT) has become the treatment modality of choice for certain stages of laryngeal carcinomas. Nevertheless, it should be kept in mind that each treatment has its difficulties and complications. Numerous complications are observed throughout the RT treatment of, for instance, skin injury, mucosal oedema, perichondritis, and necrosis [1]. Despite the beneficial nature of RT, it also has certain harmful outcomes on the neighbouring tissues, and those consequences may appear at early or late stages. Dry mouth, inflammation of the mucosa, and osteoradionecrosis are some of the examples of these side effects [2].

Lately, several studies about managing the side-effects of RT have been performed, and exogenous or herbal antioxidant molecules, numerous chemical products, vitamins, trace elements, and hyperbaric oxygen (HBO) have been used [3]. HBO has been extensively preferred for the management of numerous disorders for decades. Management of diabetic lesions, necrosis of the flap, and sudden hearing loss are a selection of cases [4]. The most common side effect is the effect of pressure change on the ear and sinuses. This is not dangerous and can be avoided by learning pressure equalisation methods. Other side effects are very rare and can be listed as oxygen poisoning, claustrophobia (fear of staying in a sheltered place), and transient myopia. Hyperbaric oxygen treatment (HBOT) has been recommended for late RT injury (necrosis) of the soft tissue and bone [5]. Herein, we reported a case with long-term side effects of RT applied for the treatment of laryngeal cancer, who were treated successfully with $\mathrm{HBO}$.

\section{Case report}

Endoscopic examination of a 58-year-old male patient performed because of hoarseness revealed a mass on the right vocal cord. The mass was biopsied, and computed tomograms (CT) of his neck were obtained. The CT result was within normal limits, and histopathological analysis of the biopsy specimen was reported as well-differentiated epidermoid carcinoma. RT was planned for the patient with stage 1 glottic laryngeal carcinoma. The patient was treated with intensity-modulated radiotherapy (IMRT) technique, and 72 Gy external RT with 200 cGy/fraction was applied to the glottic area. $2.5 \mathrm{~cm}$ sliced thickness actual treatment images acquired with a CT-simulator has been transferred into a Hi-Art tomotherapy treatment system. 
Clinical target volume (CTV) was contoured by the same physician to encompass the thyroid with a 5 -mm margin anteriorly, cricoid cartilages, arytenoid cartilage, false vocal cords, anterior and posterior commissures, true vocal cords, and 1-1.5 cm of subglottis; the borders were extended to the hyoid bone superiorly and to the bottom of the cricoid inferiorly. CTV was modified to encompass predelineated gross tumour volume. CTV was truncated within $3 \mathrm{~mm}$ of the skin surface to avoid high skin dose in patients without anterior commissure involvement. Planning target volumes (PTV) was created giving a 5-mm margin around the CTV. The spinal cord and carotid arteries were defined as critical structures.

The patient, who was kept under our routine monitorisation, occasionally complained of hoarseness, and shortness of breath three months after RT. Meanwhile endoscopic examination revealed the presence of laryngeal oedema. Low-dose oral (16 mg) corticosteroid (CTCS) treatment was initiated. His complaints were partially relieved so treatment with CTCS was tapered and finally stopped within 15 days. Nearly one week after discontinuation of the drug he started to complain of hoarseness again. On physical examination laryngeal oedema was detected again, and oral CTCS treatment was restarted. Within nearly one year his oedema decreased, and his shortness of breath relieved under CTCS treatment from time to time, and his final endoscopic control demonstrated severe impairment of vocal cord mobility or fixation of one cord, and marked oedema, which was accepted as grade III radionecrosis.

Hyperbaric oxygen therapy (HBOT) was planned for the patient for the treatment of this complication, which developed nearly one year after termination of external RT. The patient was made to breath $100 \%$ oxygen with a mask for 90 minutes within two hours at 2.4 atmospheric pressure in a decompression chamber (10 min compression, 30 min oxygen, 5 min break, 30 min oxygen, 5 min break, 10 min decompression). At admission, 30 days of HBOT was planned; however, HBOT was discontinued at the $19^{\text {th }}$ session upon symptomatic improvement. Two years after RT, the patient has no symptomatic complaints, and his endoscopic examination is unremarkable.

\section{Discussion}

For the management of head and neck cancers, radiotherapy is preferred as a primary or adjuvant treatment modality. RT of the neck may be accomplished in the occurrence of metastatic lymph node from the larynx, or of any other cancers, or in the different stages of cancer of the larynx [6].

Long-standing hypo-vascularity causes late RT complications to occur typically following a latent period of approximately three months [7]. The most commonly faced complication is laryngeal oedema, which is also the first symptom of chondronecrosis. This situation might cause late or false diagnosis. The degree of laryngeal oedema clearance is associated with the dose of RT, volume of the radiated tissue, adding up of neck dissection, and the original lesion's size and extent. The furthermost complication is continuing oedema of the larynx, which arises in $13.7 \%$ of cases with a dose less than 70 Gy, and $46.2 \%$ with a dose higher than $70 \mathrm{~Gy}$.

Chandler categorised radionecrosis of the larynx into four grades with minimal to moderate hoarseness and dryness observed in the initial two grades [8] (Table 1). As minor telangiectasia and oedema were observed in the mentioned two grades, symptomatic management with the aid of humidification, nutritional support, comprehensive voice cessation, and meticulous cessation of smoking, and imaging to exclude tumour recurrence were recommended. According to Chandler classification for laryngeal radionecrosis, grade III symptoms are severe hoarseness, moderate odynophagia, and dysphagia; while the signs are severe impairment of vocal cord mobility or fixation of one cord, marked oedema, and skin changes. The treatment of choice is symptomatic care, steroids, antibiotics, and tracheostomy if needed. Grade IV symptoms are severe respiratory distress, odynophagia, weight loss, and dehydration, while signs are fistula formation, fetor oris, fixation of skin to larynx, airway obstruction, and fever. Our case was grade III based on this classification, and HBOT alternative to steroid treatment was applied, and his symptoms were relieved.

When RT was applied for the treatment of various malignancies, the neighbouring soft tissue or even bone can be injured. The findings of radiation injury can manifest months or years later. These findings include delay in

Table 1. Chandler classification for laryngeal radionecrosis [8]

$\begin{array}{lll}\text { Symptoms } & \text { Signs } & \text { Treatment } \\ \begin{array}{l}\text { Grade I } \\ \text { Slight hoarseness, slight dryness }\end{array} & \text { Slight oedema, telangiectasia } & \begin{array}{l}\text { Symptomatic care: humidification, anti- } \\ \text { reflux therapy, smoking cessation }\end{array} \\ \begin{array}{l}\text { Grade II } \\ \text { Moderate hoarseness, moderate }\end{array} & \text { Slight oedema, telangiectasia } & \begin{array}{l}\text { Symptomatic care: humidification, anti- } \\ \text { reflux therapy, smoking cessation }\end{array} \\ \begin{array}{l}\text { Grade III } \\ \text { Severe hoarseness with dyspnoea, } \\ \text { moderate odynophagia and dysphagia }\end{array} & \begin{array}{l}\text { Severe impairment of vocal cord mobility or } \\ \text { fixation of one cord, marked oedema, skin }\end{array} & \text { Symptomatic care + steroids, antibiotics, } \\ \begin{array}{l}\text { Grade IV } \\ \text { Respiratory, distress, severe } \\ \text { odynophagia, weight loss dehydration }\end{array} & \text { Fistula, fetor oris, fixation of skin to larynx, } & \text { Tracheotomy and/or laryngectomy } \\ \end{array}$


wound healing, chronic infections, pathologic fractures, and tissue necrosis. Aetiologies of soft tissue injury include progressive endarteritis and tissue hypoxia secondary to fibrotic tissue reaction. Subsequently, radionecrosis, radiodermatitis, radiation mucositis, local pains, fistulas, and chronic infections develop. Studies performed have demonstrated greater scale effectiveness of HBOT in the success of both reconstruction of the tissue damage and healing of radionecrosis. HBOT plays a role in the healing of soft tissue and bone damage, in decreasing pain, and it is recommended as a novel adjuvant treatment in the treatment of radionecrosis $[4,5]$. HBOT helps to repair vascular beds in head and neck tissues exposed to radiation and promotes neovascularisation and wound healing [5]. Filntisis et al. retrospectively evaluated 18 patients and detected functional and symptomatic improvement in 13 (72\%), treatment failure in four, and development of recurrence in one patient. In that study, two patients of grade III and 16 patients of grade IV radionecrosis treated with HBO presented major recovery, and none of the patients required total laryngectomy [9]. Ferguson et al. [10] reported the effectiveness of HBO therapy in eight patients with laryngeal necrosis. Four of the eight patients were Chandler's grade IV laryngeal necrosis. Signs and symptoms of radionecrosis were markedly ameliorated in seven of the eight patients. Only one patient required laryngectomy. Feldmeier et al. [11] reported that nine patients (eight were Chandler's grade IV, and the ninth was grade III) with laryngeal necrosis were treated using HBO. All patients with tracheostomies could be decannulated and the fistulae were closed. All nine patients were able to maintain their voice until death or the last follow-up. Abe et al. [12] reported the effectiveness of HBO therapy in a patient of laryngeal radionecrosis. The patient received radical chemoradiotherapy (CRT) for mesopharyngeal cancer. After completion of CRT the patient developed dyspnoea with throat pain at nine months. Vocal cord impairment because of severe laryngeal oedema was revealed with laryngoscopy. The patient initially received conservative therapy combined with antibiotics, steroids, and prostaglandins. despite this treatment the patient's dyspnoea was persistent, so $\mathrm{HBO}$ therapy was administered. After 20 sessions, the dyspnoea was in complete remission. HBO therapy, therefore, is regarded as an effective conservative therapeutic option for laryngeal radionecrosis.

\section{Conclusions}

We treated a patient who developed laryngeal oedema and shortness of breath nearly one year after application of external RT for laryngeal cancer. We decreased the steroid requirement. A total of 19 times HBOT effectively treated the patient two years after the RT without any side effects.

The authors declare no conflicts of interest.

\section{References}

1. Rowley H, Walsh M, McShane D, Fraser I, O'Dwyer TP. Chondroradionecrosis of the larynx: still a diagnostic dilemma. J Laryngol Otol 1995; 109: 218-220.

2. Vudiniabola S, Pirone C, Williamson J, Goss AN. Hyperbaric oxygen in the therapeutic management of osteoradionecrosis of the facial bones. Int J Oral Maxillofac Surg 2000; 29: 435-438.

3. Sangro B, Martínez-Urbistondo D, Bester L, et al. Prevention and treatment of complications of selective internal radiation therapy: Expert guidance and systematic review. Hepatology 2017; 66: 969-982.

4. Xie XG, Zhang M, Dai YK, Ding MS, Meng SD. Combination of vascular endothelial growth factor-loaded microspheres andhyperbaric oxygen on random skin flap survival in rats. Exp Ther Med 2015; 10: 954-958.

5. Feldmeier JJ, Heimbach RD, Davolt DA, Court WS, Stegmann BJ, Sheffield PJ. Hyperbaric oxygen as an adjunctive treatment for delayed radiation injury of the chest wall: a retrospective review of twenty-three cases. Undersea Hyperb Med 1995; 22: 383-393.

6. Bekiroglu F, Wright S, Grew N. Chondroradionecrosis of larynx following radiotherapy for metastatic neck disease originating from oral carcinoma. Int J Oral Maxillofac Surg 2007; 36: 459-461.

7. Takiguchi Y, Okamura HO, Kitamura K, Kishimoto S. Late laryngo-tracheal cartilage necrosis with external fistula 44 years after radiotherapy. J Laryngol Otol 2003; 117: 658-659.

8. Chandler JR. Radiation fibrosis and necrosis of the larynx. Ann Otol Rhinol Laryngol 1979; 88: 509-514.

9. Filntisis GA, Moon RE, Kraft KL, Farmer JC, Scher RL, Piantadosi CA. Laryngeal radionecrosis and hyperbaric oxygen therapy: report of 18 cases and review of the literature. Ann Otol Rhinol Laryngol 2000; 109: 554-562.

10. Ferguson BJ, Hudson WR, Farmer JC Jr. Hyperbaric oxygen therapy for laryngeal radionecrosis. Ann Otol Rhinol Laryngol 1987; 96: 1-6.

11. Feldmeier JJ, Lange JD, Cox SD, et al. Hyperbaric oxygen as a prophylactic or treatment for radiation myelitis. Undersea Hyperb Med 1993; 20: 249-255.

12. Abe M, Shioyama Y, Terashima K, Matsuo M, Hara I, Uehara S. Successful hyperbaric oxygen therapy for laryngeal radionecrosis after chemoradiotherapy for mesopharyngeal cancer: case report and literature review. Jpn J Radiol 2012; 30: 340-344.

\section{Address for correspondence}

\section{Gonca Hanedan Uslu}

Department of Radiation Oncology

Kanuni Research and Education Hospital

Mahallesi Topal Osman Sokak No. 7

61290 Yomra, Trabzon, Turkey

e-mail: drgoncahanedanuslu@hotmail.com

Submitted: 23.05 .2018

Accepted: 21.07 .2018 